\title{
Safety assessment of an artificial intertidal flat using MASW technology
}

\author{
Yoichi Watabe $^{\text {i) }}$, Shinji Sassa ${ }^{\text {i) }}$, Takashi Kaneko ${ }^{\text {i) }}$, Kazuhiko Ueno ${ }^{\text {ii) }}$ and Koichi Yamada ${ }^{\text {ii) }}$ \\ i) Port and Airport Research Institute, 3-1-1 Nagase, Yokosuka 239-0826, Japan. \\ ii) Institute of Technology, Penta-Ocean Construction Co., Ltd., 1534-1 Yonku-cho, Nasushiobara 329-2746, Japan.
}

\begin{abstract}
Dredged soils from navigation channel or anchorage area have been used in reclamation of artificial intertidal flats in Japan. Immediately after the reclamation, because the dredged clay filled in the intertidal flat has not consolidated, a safety assessment system is strongly required to avoid depression of foot into an extremely soft soil at a place where sand capping is significantly thin. In addition, temporal variation of the dredged soils filled in the intertidal flats has not been clarified yet. In this study, a follow up research at an artificial intertidal flat in Tokuyama-Kudamatsu Port, Yamaguchi, Japan, was periodically conducted for several years since its completion of reclamation in 2008. Shear wave velocity obtained by MASW in the extremely soft sediments was only $25 \mathrm{~m} / \mathrm{s}$. Gradual increase with elapsed time in shear strength of dredged soil layer was mostly caused by chemical bonding (thixotropy effect) rather than densification (consolidation). Because MASW can describe both the thickness of sand capping and softness of the dredged soils, this technology is useful to assess the safety of artificial intertidal flats.
\end{abstract}

Keywords: shear wave velocity, multi-channel analysis of surface waves, MASW, artificial intertidal flat, consolidation, thixotropy

\section{INTRODUCTION}

Dredged soils from navigation channel or anchorage area have been used in construction of artificial intertidal flats in various regions in Japan. The dredged soils filled in the artificial intertidal flats are generally covered by sand capping with a thickness of $0.5 \mathrm{~m}$ to provide either habitat field for fishery products such as clams or recreation field for leisure activity.

Most of previous studies on artificial intertidal flats

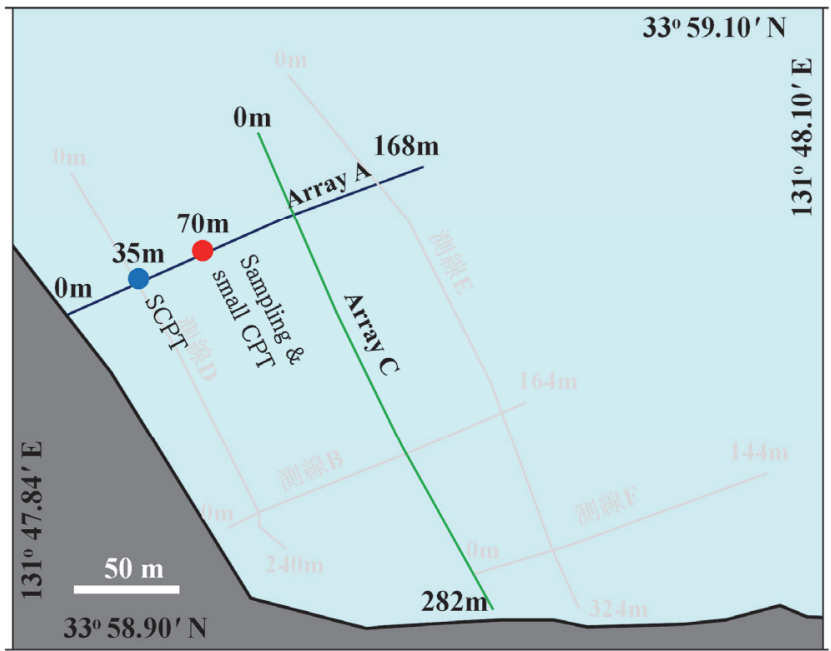

Figure 1. Arrays A and C for MASW measurement, and sampling points at 35 and $70 \mathrm{~m}$ on array $\mathrm{A}$. have focused on morphodynamics in sand capping under tidal current and ocean waves; however, temporal variation of the dredged soils filled in the intertidal flat has not been clarified yet. In this study, follow up research at an artificial intertidal flat in TokuyamaKudamatsu Port, Yamaguchi, Japan, was periodically conducted for several years since its completion of filling in 2008, focusing on the temporal variation in physical and mechanical properties of the dredged soils. Detailed information on the construction of the artificial intertidal flat is written in Ueno et al. (2012).

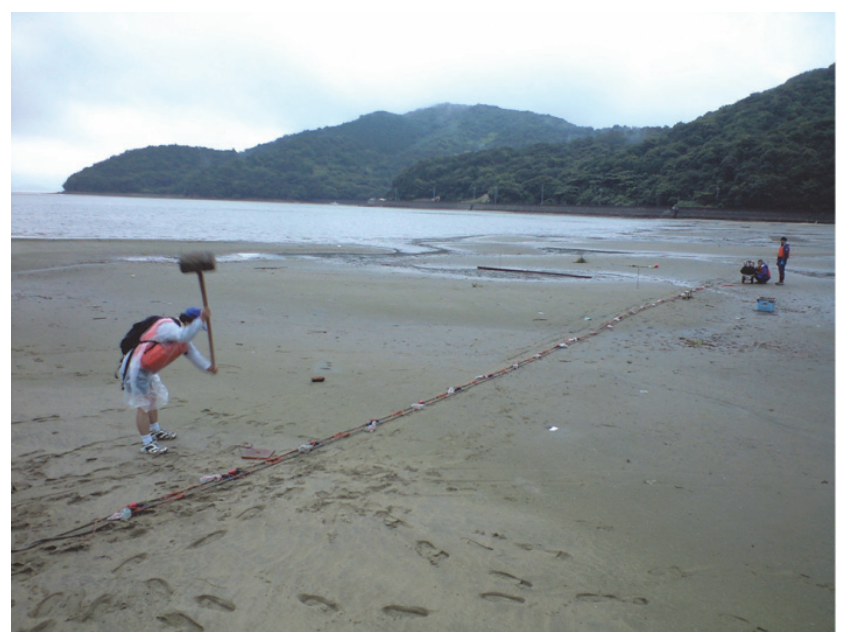

Figure 2. A typical scene of MASW measurement. 


\section{MULTI-CHANNEL ANALYSIS OF SURFACE WAVES (MASW)}

The authors have been conducting multi-channel analysis of surface waves: MASW (Park et al. 1999; Hayashi and Suzuki 2004) at intertidal flats with various characteristics (Watabe and Sassa 2008; 2012). In this study, MASW survey was conducted along the arrays shown in Figure 1 at the artificial intertidal flat in Tokuyama-Kudamatsu Port, Yamaguchi, Japan. A typical scene conducting MASW is shown in Figure 2. Shear wave velocity structures along the arrays in cross-shore direction and along-shore direction obtained from the surveys on (a) 27 to 28 April 2009 and (b) 4 to 6 July 2012 are shown in Figures 3 and 4, respectively. The shear wave velocity structure corresponds to spatial distribution of soil stiffness because of the following equation:

$$
G_{0}=\rho_{\mathrm{t}} \times v_{\mathrm{s}}^{2}
$$

Where $G_{0}$ is the shear modulus; $\rho_{\mathrm{t}}$ is the bulk density; and $v_{\mathrm{s}}$ is the shear wave velocity.

To draw these figures, inversion analysis using the measured wave patterns was conducted with the aid of a bathymetric chart measured before filling of dredged soil. In the result of MASW conducted just after reclamation (Watabe et al. 2010), shear wave velocities at deeper portion obtained by inversion analysis for the observed wave patterns was doubtable because significant attenuation occurred in propagation of shear waves in the very soft clay layer. In fact, from a comparison between the shear wave velocity structure obtained by MASW and the bathymetric chart, the very soft dredged clay layer described by MASW was extended deeper than the original seabed. To solve this problem, in this study, inversion analysis was conducted by assuming an initial model for shear wave velocity distribution reflecting the bathymetric chart, and then Figures 3 and 4 were obtained.

The sand capping was captured as a layer with slightly higher shear wave velocity. Because extremely soft dredged clay was confined in this artificial
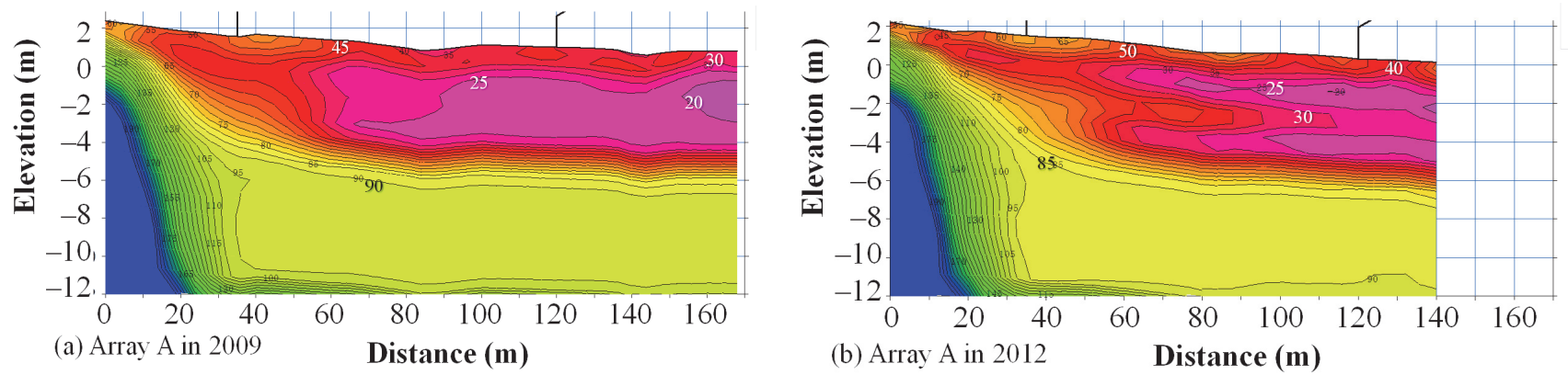

Figure 3. Shear wave velocity structure in cross-shore direction (array A).

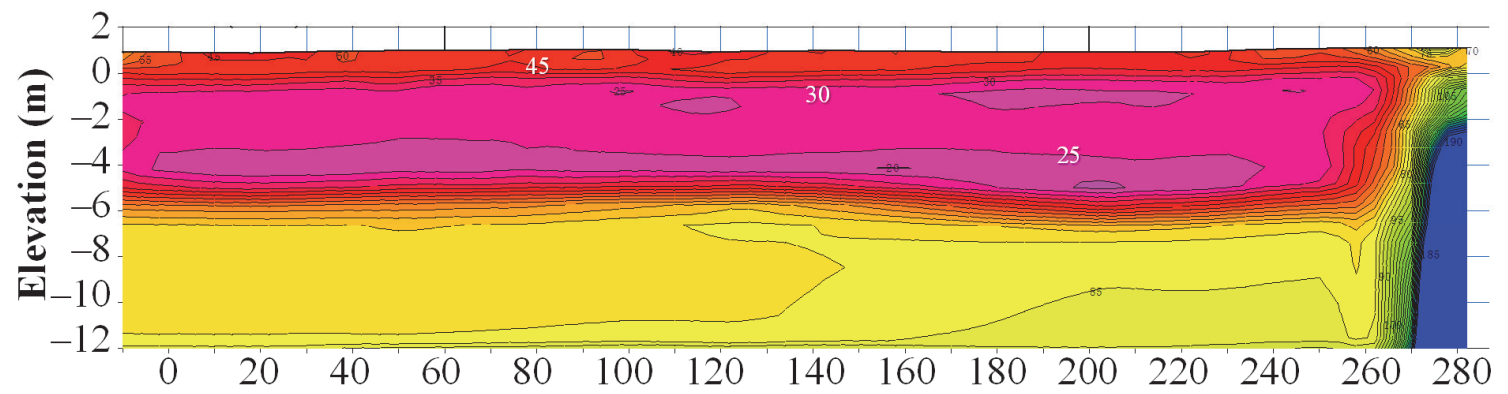

(a) Array C in 2009

Distance (m)

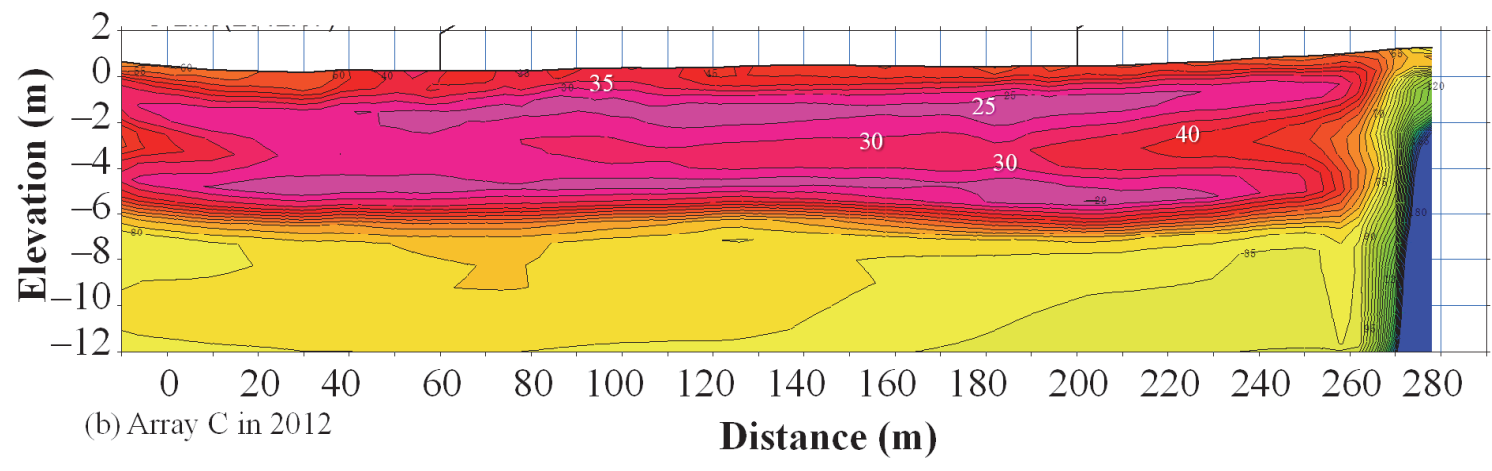

Shear wave velocity $(\mathrm{m} / \mathrm{s})$

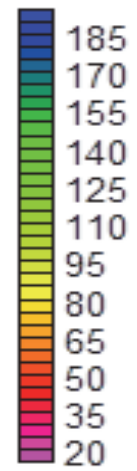

Figure 4. Shear wave velocity structure in along-shore direction (array C). 
intertidal flat, a certain thickness of the sand capping was required to prevent from depression of foot in walking on the surface for leisure use. Thickness information of sand capping is very important in regard to ensuring safety particularly at the moment just after reclamation with dredged soils. From the figures, sand capping can be seen as a surface layer with a homogeneous thickness.

In the result of inversion analysis, comprehensive understanding is important rather than detailed understanding focused on local variations. From this viewpoint, a slight increase in shear wave velocity from 2009 to 2012 was observed, indicating that the stability of the dredged soil layer confined in the artificial intertidal flat was gradually increased. In fact, when we walked on the surface of the artificial intertidal flat in 2009 just after reclamation of dredged soils, there are many unstable spots where our steps depressed significantly; however, in 2012, we confirmed that the surface is very stable for our steps. Shear wave velocities obtained by MASW in 2012 were only around $25 \mathrm{~m} / \mathrm{s}$ inside of the dredged soil layer, which is almost the same as that initially obtained just after reclamation, although more than three years had elapsed after completion of filling.

\section{SAMPLING AND SOUNDING}

From 2009 to 2012, depth profile of water content was measured for samples collected by fixed piston sampler with a diameter of $30 \mathrm{~mm}$, and from 2009 to 2013, depth profile of undrained shear strength was evaluated by small-sized electric cone penetration test (small-CPT). Detailed descriptions of the measurements conducted from 2009 to 2012 were reported in Ueno et al. (2012). From 11 to 12 March 2013, undisturbed samples with $60-\mathrm{mm}$ diameter and $500-\mathrm{mm}$ length were collected by thin-walled tube sampler with fixed piston (Watabe et al. 2013) at every 500-mm depth from surface sand capping layer to the

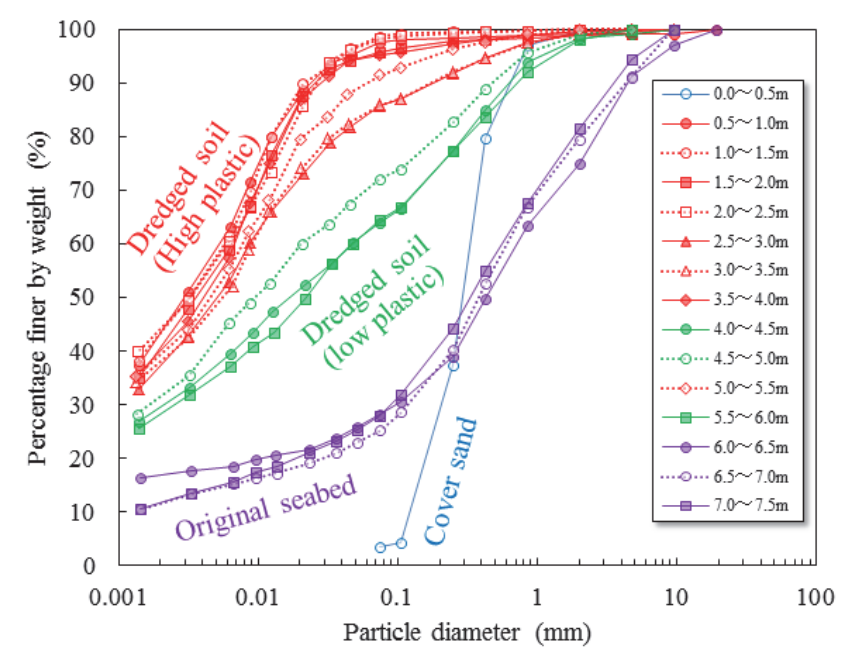

Figure 5. Grain-size distribution curve. original sandy seabed soil. For the collected samples, water content, grain-size distribution, and vane shear strength were examined. In addition, oedometer tests were conducted for the samples collected at three depths (upper and lower dredged soils and original seabed soil). The test results are shown in Figures 5 to 9.

The grain-size distribution (Figure 5) and depth profile of water content (Figure 6) show that the upper portion of the dredged soil layer was high plastic (fine particle fraction is larger than $85 \%$ ), the lower portion of the dredged soil layer was low plastic (fine particle fraction is in a range of 60 to $70 \%$ ), and these high and low plastic soils alternately deposited at the depth around their interface. The original seabed soils laid below the dredged soils was sandy (fine particle fraction less than 20\%). For all of these soils with various plasticity and water contents, natural water content coincided with the liquid limit at any depth. This fact indicates that the tendency of decreasing water content with depth was caused by the depth profile of inherent soil properties rather than a progress of consolidation. It is notable that this tendency of depth profile in water content never obtained as a result of self-weight consolidation initiated from homogeneous clay slurry at shallower depth.

If we assume self-weight consolidation in the upper high-plastic clay layer, decrement of void ratio is supposed to be at most 0.5 on the basis of Figure 8 . The decrement of 0.5 in void ratio can be transformed into a decrement of $18 \%$ in water content. The decrement of water content seen in Figure 6 is; however, much

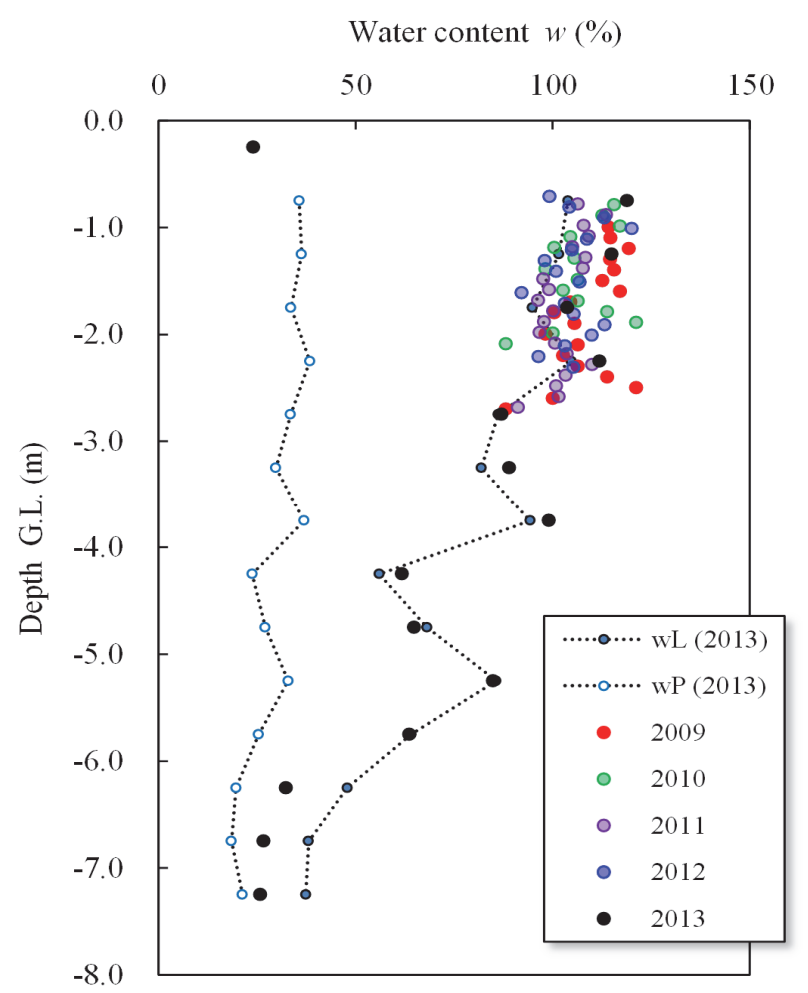

Figure 6. Consistency properties (depth profiles of water content). 
smaller than this, indicating that self-weight consolidation had not significantly progressed in 4 years after the reclamation.

Small sized electric cone penetration test (Small-CPT) was periodically conducted to measure the depth profile of tip penetration resistance $q_{\mathrm{t}}$. In the depth profile of tip resistance (Figure 7), measured value gradually increases with elapsed time. This tendency is consistent with the result that shear wave velocity obtained by MASW slightly increased from 2009 to 2013 in Figures 3 and 4. The tip resistance $q_{\mathrm{t}}$ measured in 2013 had become approximately twice of that measured in 2009.

Before extruding the collected samples from the fixed piston tube sampler in 2013, vane shear test (15-mm in width and $30 \mathrm{~mm}$ in height) was conducted and shear strength $\tau_{\mathrm{f}}$ at the tip of the sampler was obtained. In Figure 7, the horizontal axis for cone tip penetration resistance $q_{\mathrm{t}}$ in 2013 is adjusted to the vane shear strength $\tau_{\mathrm{f}}$ in 2013. Undrained shear strength $c_{\mathrm{u}}$ (equivalent to the vane shear strength $\tau_{\mathrm{f}}$ ) is generally expressed using the cone tip penetration resistance $q_{\mathrm{t}}$ as follows:

$$
c_{\mathrm{u}}=\frac{q_{\mathrm{t}}-\sigma_{\mathrm{v} 0}}{N_{\mathrm{kt}}}
$$

where, $\sigma_{\mathrm{v} 0}$ is the overburden total stress, and $N_{\mathrm{kt}}$ is a constant named as cone factor. Therefore, $\tau_{\mathrm{f}}$ and $q_{\mathrm{t}}-\sigma_{\mathrm{v} 0}$

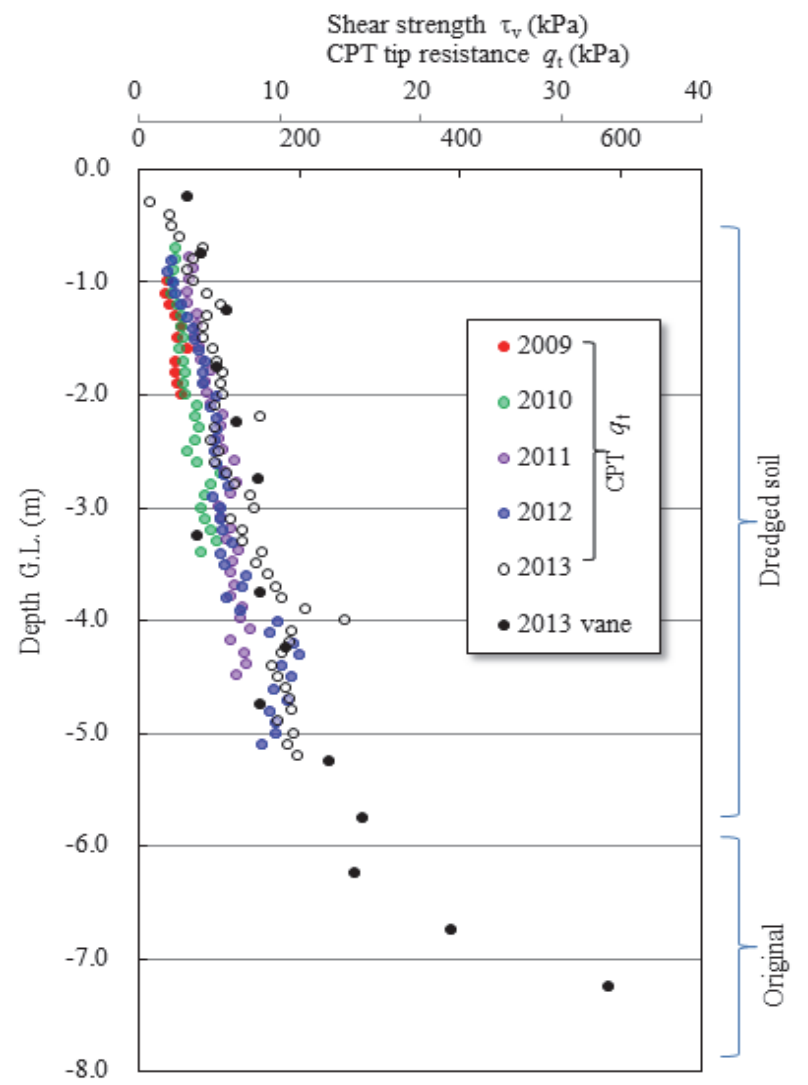

Figure 7. Depth profiles of undrained shear strength obtained by vane shear test and small CPT. should be compared rather than $\tau_{\mathrm{f}}$ and $q_{\mathrm{t}}$. Because both $q_{\mathrm{t}}$ and $\sigma_{\mathrm{v} 0}$ are expressed as straight lines and pass the origin point of the graph, i.e., both tend to linearly increase with depth, we decided to compare $\tau_{\mathrm{f}}$ and $q_{\mathrm{t}}$ without using $\sigma_{\mathrm{v} 0}$, which couldn't be directly measured.

There was a tendency that undrained shear strength linearly increased with depth in the dredged soil layer, and shear strength significantly increased with depth in the original seabed soil. This indicates that existing of low plastic soils deposited at the deeper portion of dredged soil layer (G.L. -4.0 to $-5.0 \mathrm{~m}$, and G.L. -4.0 to $-5.0 \mathrm{~m}$ ) did not influence on the depth profile of shear strength.

Using the undisturbed samples collected by the thin-walled tube sampler with fixed piston, incremental loading oedometer test (JIS A 1217: 2009) was conducted. From the compression curves (Figure 8), the surface high plastic soil (G.L. -1.0 to $-1.5 \mathrm{~m}$ ) showed high compressibility with the initial void ratio $e_{0}$ of around 3.0 and compression index $C_{\mathrm{c}}$ of around 1.0.

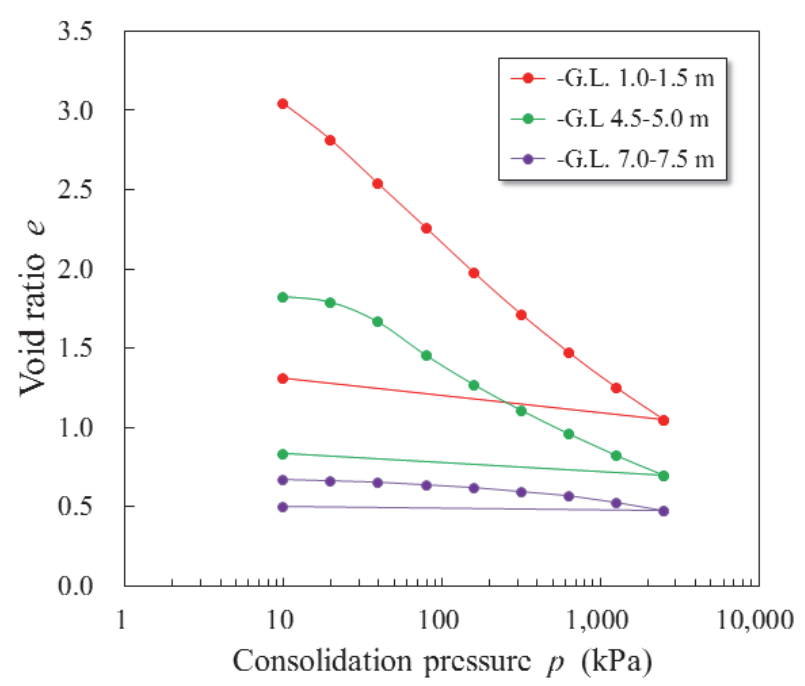

Figure 8. Compression curves.

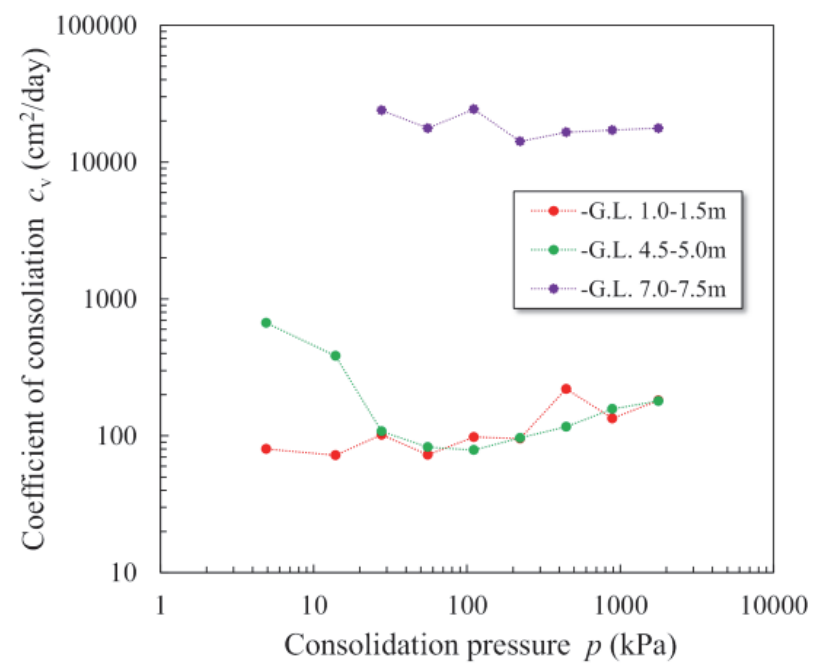

Figure 9. Relationship between coefficient of consolidation and consolidation pressure. 
Because the overburden effective stress $\sigma_{\mathrm{v} 0}^{\prime}$ was very small at this depth, whole of the compression curve obtained by the oedometer test can be approximated as a straight line in normal consolidation domain. The dredged soils at the middle depth (G.L. -4.5 to $-5.0 \mathrm{~m}$ ) had the initial void ratio $e_{0}$ of around 1.8 and compression index $C_{\mathrm{c}}$ of around 0.8 , showing a transition from overconsolidation domain to normal consolidation domain. The original seabed soil (G.L. -7.0 to $-7.5 \mathrm{~m}$ ) had the initial void ratio of 0.7 and a small compression index corresponding to a mild and concave slope in compression curve, resulting in a very small settlement.

Coefficient of consolidation $c_{\mathrm{v}}$ for the dredged soils in normal consolidation domain was around 100 $\mathrm{cm}^{2} /$ day (Figure 9). This value was common for soils with different plasticity, i.e., the upper high-plastic and lower low-plastic soils. Coefficient of consolidation $c_{\mathrm{V}}$ for the sandy original seabed soil was larger than $10,000 \mathrm{~cm}^{2} /$ day, indicating that this soil layer can be assumed to be a drainage layer. Therefore, at the point studied in this study (70 m on array A in Figure 1), dredged soil layer having a thickness of $5.5 \mathrm{~m}$ (G.L. -0.5 to $-6.0 \mathrm{~m}$ ) with double drainage boundaries required around 1.8 years for $90 \%$ consolidation, indicating that self-weight consolidation had been over in 2013. Although self-weight consolidation had been almost completed and undrained shear strength significantly increased, decrement of water content was much smaller than that anticipated. This fact indicates that most of the increment in shear strength was caused by chemical bonding (thixotropy effect) rather than densification (consolidation).

\section{CONCLUSIONS}

A series of periodical MASW survey can efficiently measure the temporal and spatial variation of soil stiffness of dredged soils filled in artificial intertidal flats. It is notable here that inversion analysis for MASW measurement is better to be calculated taking account of bathymetric chart measured before reclamation, because shear waves significantly attenuate in such soft soil layer. Gradual increase with elapsed time in shear strength of dredged soil layer filled in the artificial intertidal flat mostly caused by chemical bonding (thixotropy effect) rather than densification (consolidation). Because MASW can describe both the thickness of sand capping and softness of the dredged soils, this technology is useful to assess the safety of artificial intertidal flats.

\section{ACKNOWLEDGEMENTS}

This study was a part of the collaborative research between Port and Airport Research Institute and Penta-Ocean Construction Co., Ltd. The field measurements were conducted in cooperation with Chugoku Regional Development Bureau of Ministry of
Land, Infrastructure, Transport and Tourism, Japan, Koa Kaihatsu Co., Ltd., and Penta Techno Service Co., Ltd.

\section{REFERENCES}

1) Hayashi, K. and Suzuki, H. (2004): CMP cross-correlation analysis of multi-channel surface-wave data, Exploration Geophysics, Vol. 35, pp. 7-13.

2) JIS A 1217 (2009): Test method for one-dimensional consolidation properties of soils using incremental loading, Japanese Industrial Standard.

3) Park, C.B., Miller, R.D., Xia, J. (1999): Multichannel analysis of surface waves, Geophysics, Vol.64, No.3, pp.800-808.

4) Ueno, K., Kikuhara, N., Yamada, K. and Watabe, Y. (2012): Research on the reclamation and consolidation of an artificial tidal flat filled with dredged clay, Journal of Japan Society of Civil Engineers B3, Vol.68, No.2, pp.1079-1084. (in Japanese) DOI: 10.2208/jscejoe.68.I_1079

5) Watabe, Y. and Sassa, S. (2008): Application of MASW technology to identification of tidal flat stratigraphy and its geoenvironmental interpretation, Marine Geology, Vol.252, pp.79-88. DOI: 10.1016/j.margeo.2008.03.007

6) Watabe, Y. and Sassa, S. (2012): Sedimentary stratigraphy of natural intertidal flats with various characteristics, Soils and Foundations, Vol.52, No.3, pp.411-429.

DOI: 10.1016/j.sandf.2012.05.003

7) Watabe, Y., Sassa, S., Hayashi, K. and Yamada, K. (2010): Applicability of MASW technology to safety assessment of artificial intertidal flats, Journal of Japan Society of Civil Engineers B2, Vol.66, No.1, pp.1406-1410. (in Japanese) DOI: 10.2208/kaigan.66.1406

8) Watabe, Y., Sassa, S. and Nakajima, M. (2013): Verification of the sedimentation history of the sand bars in the entrance of Tofutsu Lake evaluated by MASW, Journal of Japan Society of Civil Engineers B2, Vol.69, No.2, pp.1411-1415. (in Japanese) DOI: 10.2208/kaigan.69.I_1411 